\title{
ENGINEERING DEVELOPMENT OF CERAMIC MEMBRANE REACTORSYSTEM CONVERTING NATURAL GAS TO HYDROGEN AND SYNTHESIS GAS FOR LIQUID TRANSPORTION FUELS
}

Monthly Status Report Period Ending: 02/31/1999

DOE Award NO.: DE-FC26-97FT96052--23 
1000 Independence Avenue, S.W.

Washington, DC 20585

\title{
ENGINEERING DEVELOPMENT OF CERAMIC MEMBRANE REACTOR SYSTEM FOR CONVERTING NATURAL GAS TO HYDROGEN AND SYNTHESIS GAS FOR LIQUID TRANSPORTATION FUELS
}

\author{
Monthly Status Report \\ February 1999
}

\section{Contract Objectives}

The objective of this contract is to research, develop and demonstrate a novel ceramic membrane reactor system for the low-cost conversion of natural gas to synthesis gas and hydrogen for liquid transportation fuels: the ITM Syngas process. Through an eight-year, three-phase program, the technology will be developed and scaled up to obtain the technical, engineering, operating and economic data necessary for the final step to full commercialization of the Gas-to-Liquids (GTL) conversion technology.

\section{Summary of Activity}

\section{Task 1.1 Process Engineering and Economics}

\section{Task 1.1.1 Process Design and Engineering}

The "conceptual-stage" baseline ITM Syngas process with an adiabatic pre-reformer is being refined to develop the "preliminary-stage" process design for both the land-based GTL plant (500 MMSCFD associated gas feed) and the offshore GTL plant (50 MMSCFD associated gas feed). Process design and economics of downstream operations (Fischer-Tropsch and hydrocracking) will be kept to a "conceptual" stage.

The design basis for the offshore, Gulf Coast, economic analysis was changed from a fixed platform to a Floating Production, Storage, and Offloading (FPSO) system based on input from the project team. During Phase I, the offshore evaluation will compare the capital cost of the ITM Syngas generation process with an ATR process on a $\$ / \mathrm{ft}^{2}$ of deck space basis. Also, McDermott's scope was expanded to include evaluation of land-based ITM Syngas process economics. This evaluation will be at a conceptual level and will include a Gulf Coast base case and an Alaskan North Slope case.

Chevron continued process development of an integrated ITM Syngas Gas-to-Liquids (GTL) plant. A non-optimized Aspen simulation model of the GTL plant was completed. The model includes the ITM, Fischer-Tropsch (FT), and upgrading sections, as well as key utility systems (e.g., steam and power). As expected the thermal efficiency of the plant is around 60\%. Future work will increase efficiency by improving the use of off-gases and produced steam. 
Norsk Hydro initiated preliminary-stage process design refinement for a large-scale (150 MMSCFD $\mathrm{H}_{2}$ ) ITM H2 process for fuel-grade hydrogen. Aspen simulations, heat and material balances, and process equipment definitions are being completed for ITM H2 processes using either adiabatic or GHR pre-reformers. Process efficiencies are being compared to conventional technology.

Specifications for "distributed" ITM H2 for Fuel Cell Vehicle refueling applications were developed. A

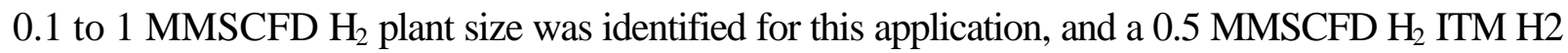
process is being developed. To achieve capital cost savings, heat exchangers, ITM conditions, and high-temperature shift reactor conditions are being optimized.

\section{Task 1.1.2 Commercial-Scale Plant Economic Evaluation}

Capital cost estimates are proceeding in parallel with the "preliminary-stage" process design for ITM Syngas and large-scale ITM H2. In addition, utility balances (e.g., steam and power) are being used to estimate operating costs. The land-based ITM Syngas GTL scope includes the ITM Syngas process, the FT process, the upgrading (hydrocracking) process, and off-sites. The capital cost estimate of the ITM Syngas process will be a more detailed estimate generated from the process design, while the capital cost estimates of the FT and upgrading sections will be kept at a "conceptual" level using information from available sources. During Phase I, the scope of the offshore economic comparison will focus on the syngas generation process and compare ITM Syngas to an ATR with cryogenic oxygen. The offshore economic comparison will later be expanded to include the FT and upgrading sections, as well as off-sites.

\section{Task 1.2 Materials and Seals Development}

\section{Task 1.2.1 Materials Development}

\section{Subtask 1.2.1.1 Materials Characterization and Assessment}

\section{Material Characterization}

Stability testing of I 2 and I4 materials in process gas mixtures at elevated pressure demonstrated that the addition of water did not measurably degrade the stability at $750^{\circ} \mathrm{C}$. TGA-DTA experiments were conducted under air and $\mathrm{N}_{2}$ on two stable $\mathrm{I} 2$ materials prepared by Eltron Research. The TGA indicated a large change in oxygen non-stoichiometry with temperature in air and slow exchange kinetics, suggesting potentially high chemical expansion effects.

\section{Mechanical Property Measurement}

Compressive O-ring tests were performed on an $\mathrm{I} 4$ material at 750,850 , and $950^{\circ} \mathrm{C}$ in a reducing atmosphere. The strength and Weibull parameters were found to be independent of the test atmosphere. 


\section{Subtask 1.2.1.2 Powder Production and Test Sample Fabrication}

Ceramatec prepared tubes from two stable 12 compositions. However, tubes of both compositions cracked during application of an $\mathrm{O}_{2}$ reduction catalyst, suggesting that these compositions have low surface exchange kinetics without the catalyst coating. Ceramatec also fabricated leak-tight I4 tubes for syngas testing. The I4 composition was found to be much easier to process than I2 compositions prepared in an identical manner, and this was attributed to a lower chemical expansion in the I4 material.

\section{Coating of Catalysts on Tube Surfaces}

Work continued at Eltron on dip coating catalyst layers on I2 tubes. Progress was made in depositing uniform support layers with the required thickness as determined by SEM, and a number of preparation procedures for adding the metal catalyst were investigated. SEM analysis was also carried out at Air Products to determine the uniformity of metal dispersion in the reforming catalyst layers.

\section{Subtask 1.2.1.3 Atmospheric Pressure Testing}

The atmospheric pressure reactor at Air Products was used to test tubes of two I4 compositions coated with $\mathrm{O}_{2}$ reduction catalyst on both surfaces. Tests were carried out with both $\mathrm{H}_{2}$ and $2 \% \mathrm{CH}_{4}$ in $\mathrm{He}$ feeds, producing $\mathrm{CO}_{2}$ and $\mathrm{H}_{2} \mathrm{O}$, and effective conductivities were calculated.

At Eltron, the atmospheric pressure reactors were used to evaluate tubes fabricated from stable I2 and I4 compositions and coated on opposite sides with $\mathrm{O}_{2}$ reduction catalyst and reforming catalyst. $\mathrm{GC}$ analysis was used to determine the production of $\mathrm{H}_{2}$ and $\mathrm{CO}$ and to monitor unconsumed $\mathrm{CH}_{4}, \mathrm{CO}_{2}$, $\mathrm{N}_{2}$, and other gases, if present, at the parts per million level. XRD was used to monitor the crystalline phases present in the reactor tubes and in the catalyst coatings, and to detect any reactions between tube and catalyst materials. SEM was employed to measure the thickness, porosity, degree of sintering, adherence, and crystallite size of the catalyst coatings and the grain sizes of the membrane material. Effective ionic conductivities and syngas production rates were consistent with values obtained by Air Products.

\section{Subtask 1.2.1.4 Low $\Delta P(<300$ psig $)$ Testing}

Tests were performed at Eltron in the two 300-psig reactors at elevated temperature and pressure using I4 tubular membranes and ceramic/metal seal assemblies fabricated by Ceramatec. As each reactor is assembled and brought to working conditions, the testing approach currently is fourfold. The first step is to determine the performance of the ceramic/metal seals at room temperature, and then eventually at $900^{\circ} \mathrm{C}$ and $250 \mathrm{psig}$. The second step is to operate the reactor under flowing nitrogen and test for oxygen permeation. The third step is to hold the reactor at low levels of methane and test for partial oxidation. The last is to examine the performance of the reactor hardware at temperature and pressure.

The three shakedown tests carried out this month have been utilized to (a) develop a procedure to achieve leak-free operation, (b) prevent over-heating of the upper flange and (c) regulate the mass flow controllers. Synthesis gas was produced from $\mathrm{CH}_{4} / \mathrm{N}_{2}$ feeds at $250 \mathrm{psig}$ and $850^{\circ} \mathrm{C}$, with air fed to the inside of the tubes at atmospheric pressure. For future tests, inlet gas flow rates will be adjusted to compensate for the lower conductivity of the I4 compositions. 
Work began on the design and construction of the third and fourth high-pressure reactors. Design modifications were made based on the operating experience obtained with the shakedown of the first two reactors.

\section{Subtask 1.2.1.5 High $\Delta P(<500$ psig) Testing}

Work continued on the high-pressure reactor at Air Products. Machined ceramic parts were ordered, and high-purity insulation for the vessel was specified.

\section{Task 1.2.2 Seals Development}

A total of five I4 tubes with modified ceramic/metal seal assemblies fabricated at Ceramatec were delivered to Eltron for high-pressure testing. Two of these had $\mathrm{O}_{2}$ reduction catalyst coatings on both surfaces, and three had reforming catalyst coatings on the outside and $\mathrm{O}_{2}$ reduction coatings on the inside. The first assembly tested at Eltron had mixed results, while the second assembly showed no leakage from room temperature to the full test conditions of $850^{\circ} \mathrm{C}$ and $250 \mathrm{psig}$. A seal assembly test rig was assembled at Ceramatec to pre-qualify tube/seal assemblies before they were shipped to Eltron.

\section{Task 1.3 ITM Syngas Reactor Design and Fabrication}

\section{Task 1.3.1 ITM Syngas Reactor Design and Engineering}

\section{Subtask 1.3.1.1 Mechanical/Structural Design of Membranes and Seals}

McDermott developed a bi-layer (dense and porous) tubular, finite element shell model to evaluate the stress on a tube subjected to the external pressure of the ITM reactor. Predictive methods were developed to estimate the allowable working stress for the porous layer, and initial concepts were developed for internally supported tubes.

\section{Subtask 1.3.1.2 Reaction Engineering and Kinetic Modeling}

Chevron began the formulation of a two-dimensional ITM reactor model in cylindrical coordinates. The differential species and energy balances are being written for each of four distinct regions (i.e., air side, dense membrane, catalytic oxidation, and catalytic reforming) and tied together with appropriate boundary conditions. Oxygen transport across the ITM membrane was also developed for a cylindrical coordinate system.

Norsk Hydro completed a literature study on partial oxidation of methane to carbon monoxide and hydrogen using nickel, nickel oxide, and other metal oxides. The study also included an evaluation of catalytic oxidation of carbon monoxide and hydrogen on nickel and some metal oxides.

\section{Subtask 1.3.1.3 Conceptual Reactor Vessel Engineering}

Work continued on the conceptual design of the shell-and-tube reactor concept. A significant factor affecting the size of shell-and-tube reactors is the amount of bulk reforming catalyst required. Preliminary scoping calculations for the planar reactor vessel concept will be initiated in March. The model developed for the shell-and-tube reactor will be used as a starting point for translating from a tubular to a planar geometry. 


\section{Task 1.3.2 ITM Syngas Membrane Fabrication}

\section{Subtask 1.3.2.1 Powder Production, Process Development and Scaleup}

\section{Thin Film Fabrication}

Work was initiated at Ceramatec to make planar thin-film laminates of an I4 material. Initial structures had lower porosity than anticipated. Thin-film membranes appear feasible in planar geometries, but further work is needed.

\section{Coating Thickness Control}

Efforts are underway at Ceramatec to improve the uniformity of coating thickness on the closed-end tubes fabricated for testing at Eltron and Air Products. Examinations of tested and as-fabricated tubes have shown that the coatings can vary in thickness and, in some cases, isolated regions appear to be uncoated. One complication in coating closed-end tubes is associated with the hemispherical end, and the difficulty of coating the inside of the tube at a controlled withdrawal velocity. Improved means to control by controlling the dip-coating process are being explored. 